\title{
Escolhendo um final alternativo, do parafrástico ao polissêmico
}

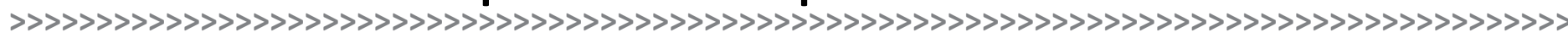

Carolina Fernandes*

Susane Andrade Rodrigues**

\section{Resumo:}

A necessidade de trabalhar a linguagem em sua discursividade, notadamente a ideologia nas práticas discursivas que constituem o sujeito, é o foco da Análise do Discurso de linha francesa. Por este viés teórico sobre o estudo da linguagem é que se propôs a leitura e posterior escrita da escolha de um dos finais alternativos sugeridos pelo livro Samanta gorducha vai ao baile das bruxas, de Kathryn Meyrick em uma turma de 4o ano do Ensino Fundamental de uma escola pública estadual do município de Sant'Ana do Livramento. O objetivo da atividade de leitura foi mostrar aos alunos que a língua não é estável, nem transparente, já que o discurso é opaco, logo permeado de historicidade e subjetividades. Portanto, vê-se que é importante o trabalho com textos que permitem a polissemia, além do debate sobre certos efeitos de evidência como o dos padrões de beleza, pois assim são fornecidas condições favoráveis ao discente de produzir sentidos, texto e discurso. O resultado obtido com esta proposta foi a percepção de que o corpo dos sujeitos é uma construção discursiva articulada com as condições de produção e a historicidade.

\section{Palavras-chave:}

Análise do discurso de linha francesa. Polissemia. Subjetividades.

\begin{abstract}
:
It is necessary to work language in its discursiveness, notably ideology in the discursive practices that make up the subject, is the focus of French Line Discourse Analysis. For this theoretical bias on the study of language is that it was proposed to read and later write the choice of one of the alternative endings suggested by the book "Samantha plumpha goes to the witch ball" by Kathryn Meyrick in a class of $4^{\text {th }}$ year of Elementary School of a state public school in the municipality of Sant'Ana do Livramento. The aim of the reading activity was to show students that the language is neither stable nor transparent, since discourse is opaque, thus permeated by historicity and subjectivity. Therefore, it is important to work with texts that allow polysemy, in addition to the debate about certain effects of evidence such as beauty standards, because this provides favorable conditions for students to produce meaning, text and discourse. The result obtained with this proposal was the perception that the body of the subjects is a discursive construction articulated with the conditions of production and historicity.
\end{abstract}

\section{Keywords:}

French discourse analysis. Polysemy. Subjectivities.
* > Doutora em Letras pela UFRGS, professora no curso de Letras e na pós-graduação da Universidade Federal do Pampa (Unipampa, campus Bagé). E-mail: carolinafernandes@unipampa.edu.br.

\footnotetext{
** > Mestranda do curso de Mestrado Profissional em Ensino de Línguas da Unipampa. Professora da educação básica da rede pública da cidade de Sant'Ana do Livramento, RS.

E-mail: susaneandrade2992@gmail.com.
} 


\section{Considerações iniciais}

Este texto discute os resultados da aplicação de uma atividade de prática de leitura realizada no quarto ano do Ensino Fundamental, tendo por base teórica a Análise de Discurso de linha francesa. Nessa perspectiva, sujeito e sentidos constituem-se mutuamente, escrever é, portanto, dizer-se no texto. E dizendo-se é que se constitui sujeito do discurso. Esse sujeito, sendo simbólico, e não um indivíduo de carne e osso, marca na linguagem sua constituição ideológica, assim, por meio do que escreve, podemos observar o modo como o sujeito discursiviza o corpo, ou melhor, sua relação com o corpo físico, que é também um construto discursivo.

A prática foi realizada no Instituto Estadual de Educação Dr. Carlos Vidal de Oliveira, que está situado no município de Sant'Ana do Livramento e atende turmas de Ensino Fundamental e Curso Normal, tendo aproximadamente 550 alunos. A escola atende um público de periferia do município, sendo predominantemente de classe econômica baixa.

A turma em que foi aplicada a intervenção pedagógica possuía 22 alunos, sendo dezessete meninas e cinco meninos. A faixa etária média era entre nove e dez anos de idade. A professora regente da turma foi uma das pesquisadoras deste artigo.

Os alunos demonstraram-se engajados nas propostas apresentadas, buscando participar e compreender o que lhes foi proposto. Talvez esta participação tenha ocorrido pelo fato de eles já estarem habituados a atividades desenvolvidas sob a perspectiva da discursividade.

A oralidade foi bem explorada durante a discussão dos textos, os alunos não tiveram receio em se posicionarem, mesmo que, muitas vezes, emitindo discursos impregnados de juízos de valor, ressaltando os erros alheios e as dificuldades em reconhecer as próprias fragilidades. Essa prática possibilitou a polissemia e a construção de sentidos pelos discentes de modo particular.

\section{A Análise do Discurso de linha francesa}

A Análise do Discurso de linha francesa (AD) “[...] é um campo de pesquisa cujo objetivo é compreender a produção social de sentidos, realizada por sujeitos históricos, por meio da materialidade das linguagens" (GREGOLIN, 2007, p. 11). Dessa forma, a AD trabalha com a materialidade linguística e os efeitos de sentido dela decorrentes. Entende-se que o sujeito não é a origem na constituição dos sentidos, já que é afetado sócio-historicamente pelos dizeres já produzidos. As ferramentas teóricas da $\mathrm{AD}$, por sua vez, permitem realizar a análise da linguagem, considerando as condições de produção, os sujeitos e o contexto sócio-histórico. Por isso, a proposta deste relato foi analisar as materialidades linguísticas produzidas pelos alunos em seus gestos de interpretação.

Após a leitura de um livro infantil que permite a polissemia, viu-se com qual final os alunos mais se identificaram, observando em quais posições-sujeito eles se inscreveram: se pela continuidade dos finais esperados em contos tradicionais ou pela ruptura através da escolha de uma formação discursiva diferente. Persistindo na continuidade, é visível a repetição no processo parafrástico pelo qual “[...] sempre algo que se mantém, isto é, o dizível, a memória” (ORLANDI, 2010, p. 36). Ao escolher o final inusitado, vemos o "deslocamento, ruptura de processos de significação e o jogo com o equívoco" (ORLANDI, 2010, p. 36), ou seja, a polissemia. Assim, o aluno, escolhendo o final inusitado, produz um gesto de leitura polissêmico, em que há criatividade na produção de sentidos, diferentemente da paráfrase, na qual impera a produtividade, a repetição do mesmo em processos já 
cristalizados. O pertinente, ao se falar em polissemia, é a possibilidade de dar voz a outros sentidos. Lembrando que todos esses processos produzem significação na historicidade.

Considerando texto como "[...] uma unidade de análise, afetada pelas condições de sua produção” (INDURSKY, 2001, p. 28), vemos que o texto se relaciona em seu aspecto simbólico estabelecendo relações com a exterioridade, buscando um efeito aparente de homogeneidade. Para a Análise do Discurso (AD), o texto não é um acumulado de sentenças objetivas, mas é passível de sentidos e, estes, ficam à deriva, em busca de gestos de interpretação. Tal entendimento precisa estar atrelado ao processo de ensino-aprendizagem em sala de aula, já que o processo de leitura também é efeito da subjetividade do sujeito-leitor que se inscreve na linguagem ao produzir sentidos para o texto. Assim, a leitura que o aluno faz deve perpassar o texto, buscando tecer redes de sentidos a partir dele, e não ser marcado pelo efeito de evidência e de objetividade, já que, ao contrário, não estaríamos abordando a língua em sua materialidade.

No entanto, não é uma questão de tudo ou nada, como observa Orlandi (2012), mas de sentidos possíveis, que são mobilizados para dar efeito de unidade ao nosso dizer. Para Indursky (2001, p. 32), “[...] só assim a ilusão de homogeneidade se instaura e o efeito-texto se produz". Dessa maneira, entendemos que textos e outros dizeres já ditos ganham aspecto de novidade ao serem reestruturados de maneira que produzam algo considerado "inédito".

Assim, não há texto que seja plenamente parafrástico ou polissêmico, mas é marcado pela tensão entre os dois, ora pendendo mais para um lado ora para o outro. No caso do conto apresentado, embora haja paráfrase, a opção de finais diferentes é marcada pela polissemia, já que há ruptura, ou seja, o deslocamento no processo de significação ao que é esperado nesse tipo de conto. Tal fato é pertinente para que os educandos consigam perceber que os fatos na produção de sentidos na língua não devem ser considerados como respostas únicas, uma vez que a língua não é produto pronto e acabado.

Tal fato pode parecer desalentador para discentes que foram acostumados, em seu percurso escolar, a considerar e corrigir suas tarefas segundo a classificação de certo ou errado. Assim, no fazer escolar, há pouco espaço e visibilidade para a criatividade propriamente dita, ou seja, sair do fator parafrástico, em que há ênfase na repetição do mesmo e, poucas vezes, a produção de sentidos diferentes dos esperados pelo professor ou pelo material didático.

Um conto em que a personagem principal lida com seu corpo acima do peso desejado traz aos alunos uma problemática presente nas condições de produção próprias da contemporaneidade. Percebe-se uma valorização do corpo considerado ideal e, assim, esse discurso permeia as formações imaginárias da sociedade como um todo, afeta o modo como o sujeito se vê e lida com seu corpo. O funcionamento da ideologia, por meio da interpelação dos indivíduos em sujeitos, se realiza através do complexo das formações ideológicas (PÊCHEUX, 1995), ou seja, tornando evidentes certas significações e não outras. Portanto, o sujeito interpelado ideologicamente interpreta determinados enunciados como sendo transparentes, reproduzindo sentidos cristalizados, a produção de evidências se faz nesse efeito de verdade ou de naturalidade, por exemplo, de que é belo o corpo magro e malhado. Então, as formações ideológicas hegemônicas fazem prevalecer um imaginário social de corpo ideal. Para Ernst (2007, p. 3-4):

Põe-se em funcionamento o ideal de indefectibilidade do corpo que se manifesta no discurso escolar em consonância com os estereótipos presentes no discurso do senso comum e, em outros, como o publicitário. Esse ideal é perseguido tenazmente por grande parte das pessoas que, julgando-se imperfeitas, necessitam de meios que lhes garantam o corpo ideal. $\mathrm{O}$ culto à juventude e à beleza, o privilégio da pele branca, $\mathrm{o}$ medo da velhice e da morte, a moda e as representações coletivas impõem cânones que só um pequeno número consegue alcançar e impedem que a maioria se sinta à vontade em seu próprio corpo e aceite sua imagem. 
É nesta perspectiva teórica que este trabalho se propõe a analisar de que forma os sujeito-alunos se posicionam com relação ao discurso sobre padrão de beleza, já que a personagem deve "encaixar-se nos padrões" para obter sucesso e chance de entrar no vestido para ir à festa almejada.

\section{Discurso sobre o corpo}

O título da obra Samanta Gorducha vai ao baile das bruxas (MEYRICK, 1995) já deixa de forma enfática o problema da personagem, já que ela é designada por "gorducha", e isso está atrelado a um imaginário social. Vê-se que o corpo é também um elemento central na constituição das identidades. Na compreensão de Vinhas (2014, p. 19), o “[...] corpo é materialidade corpórea que juntamente com a linguagem é entendido como elemento necessário para a constituição da subjetividade". Entendendo que identidade é "[...] constituída em processos de memória afetados pelo inconsciente e pela ideologia" (ORLANDI, 1998, p. 204), vemos que o estado corporal é parte da identificação, subjetivação e definição da posição-sujeito em busca de um ideal, do desejo da aparência, como afirma Pêcheux (2012, p. 34):

De nada serve negar essa necessidade (desejo) de aparência, veículo de disjunções e categorizações lógicas: essa necessidade universal de um "mundo semanticamente normal”, isto é, normatizado, começa com a relação de cada um com seu próprio corpo e seus arredores imediatos (e antes de tudo com a distribuição de bons e maus objetos, arcaicamente figurados pela disjunção entre alimento e excremento).

Percebemos que o autor entende o processo de "normalização" como o processo discursivo de encaixar tudo em padrões, dentro de categorizações lógicas, sendo estas regidas pelos veículos midiáticos que gozam da possibilidade da responsividade às demandas, $o$ controle do que inclui o modo de ver o próprio corpo. Notamos que, assim, instaura-se um controle maior sobre os sujeitos e seus corpos: “[...] esses métodos que permitem o controle minucioso das operações do corpo, que realizam a sujeição constante de suas forças e lhes impõem uma relação de docilidade-utilidade" (FOUCAULT, 2008a, p. 118). Por isso, a consciência individual sobre o próprio corpo não existe em si, ela provém de um saber cultural, legitimado e de certa forma padronizado. Revendo o conceito de subjetividade desenvolvido na $\mathrm{AD}$, notamos que o assujeitamento ideológico se dá por uma aparente homogeneidade nos discursos que produz o efeito de evidência:

\footnotetext{
Submetendo o sujeito, mas ao mesmo tempo apresentando-o como livre e responsável, o assujeitamento se faz de modo a que o discurso apareça como instrumento (límpido) do pensamento e um reflexo (justo) da realidade. Na transparência da linguagem, é a ideologia que fornece as evidências que apagam o caráter material do sentido e do sujeito. E aí que se sustenta a noção de literalidade: o sentido literal, na concepção linguística imanente, é aquele que uma palavra tem independentemente de seu uso em qualquer contexto (ORLANDI, 2010, p. 51).
}

Por sua vez, nas aulas de Língua Portuguesa, vê-se a busca pela unidade, padronização e, por isso mesmo, da busca de uma literalidade, homogeneidade e, por vezes, a metalinguagem que define o que é certo ou errado na língua. Partindo dessa ilusão provocada pelo assujeitamento ideológico, que é inconsciente, pois, nas palavras de Pêcheux (1995, p. 301): “[...] a ordem do inconsciente não coincide com a da ideologia, o 
recalque não se identifica nem com o assujeitamento nem com a repreensão, mas isso não significa que a ideologia deva ser pensada sem referência ao registro inconsciente [...]", tem-se que inconsciente e ideologia estão materializados na incompletude da língua. Diremos que o caráter material do sentido - mascarado por sua evidência para o sujeito consiste na sua dependência constitutiva e a isso chamamos de interdiscurso, quando os alunos manifestam suas "verdades" com relação ao corpo, definindo o que entendem por beleza e, assim, alocando a protagonista em lugares e possibilidades para o "final feliz", ou ainda para elas mesmas, num processo de identificação, permeado pela historicidade e as condições de produção.

\section{A obra}

Com relação à construção dessa obra destinada às crianças, não há o tom didático -pedagógico evidente e taxativo sobre o quão "errado" é ser gordo e sobre a necessidade de uma alimentação saudável, mas há o enfoque no humor que possibilita ao discente a construção de sentidos sem ênfase em padrões e estereótipos "bons" ou "maus", porém a formulação de seus próprios gestos de interpretação. Algo interessante ao leitor, também, é o modo como o texto é formulado, já que busca interagir com o leitor, saindo da estrutura aparentemente homogênea e autoritária, própria do discurso pedagógico: “[...] um dizer institucionalizado, sobre as coisas, que se garante, garantindo a instituição em que se origina e para qual tende" (ORLANDI, 2011, p. 23). No entanto, a obra apresentada permite a inserção da voz daquele que lê como se fosse uma carta ao leitor, sem o efeito autoritário. Esse tipo de carta é utilizado em situação de ausência de contato imediato entre locutor e interlocutor que não se conhecem, “[...] atendendo a diversos propósitos comunicativos como opinar, agradecer, reclamar, solicitar, elogiar, criticar etc.” (CECÍLIO, 2007, p. 2062).

Dessa forma é que se justifica que tal gênero discursivo é uma estratégia para a interação com o leitor. É possível corroborar isso por meio do seguinte recorte: “Queridos amigos, sinto muito. Não adianta fingir. Isso é o que eu chamo de final feliz! Vocês não acham?” (MEYRICK, 1995, p. 31). Serve como um convite à obra, à brincadeira com a linguagem, com os discursos e com a imagem do próprio corpo.

Por sua vez, tornou-se necessário aplicar em uma turma de Ensino Fundamental um trabalho tendo por base a obra de Meyrick. Será que os alunos vão optar pelo final clássico e esperado ou vão escolher o final inesperado? Tal aplicação tornou-se ideal em uma turma de $4^{\circ}$ ano do Ensino Fundamental em que a maioria é constituída de meninas na faixa etária de nove a dez anos. A figura do príncipe ainda está presente no imaginário das meninas? Tais questionamentos conduziram a prática à filiação teórica da $\mathrm{AD}$ francesa.

\section{Descrição da experiência}

A intervenção didática ocorreu em duas horas/aula, em uma turma de $4^{\circ}$ ano do Ensino Fundamental de uma escola estadual do município de Sant'Ana do Livramento, no estado do Rio Grande do Sul. A proposta didática, que busca trabalhar a linguagem como discursividade, partiu de atividades que tragam o texto e seu processo de significação, dentro de gestos de interpretação. Tais etapas são:

a. Escuta dos alunos sobre quais personagens ou livros que possam levar a uma identificação com a personagem;

b. Leitura do livro para os alunos;

c. Escrita individual dos alunos de sua leitura espontânea para se posicionarem quanto ao final do texto, demonstrando qual o final com o qual mais se identifica, 
inserindo este educando em um "movimento linguístico-discursivo da escrita" (LEMOS, 1998, p. 29);

d. Oralização e socialização dos argumentos da escolha por determinado final em roda de conversa.

Antes da leitura do livro, a professora solicitou oralmente que cada aluno dissesse quais são seus personagens e livros prediletos. A grande maioria dos discentes falou sobre livros de personagens próprios de programas audiovisuais comerciais. A pergunta seguinte para a turma foi se eles haviam conhecido essas personagens através da leitura de livros ou por meio de vídeos. A quase totalidade das respostas foi que primeiro viram nas mídias e posteriormente leram livros ou almanaques das personagens citadas.

Em seguida, a professora leu e mostrou as ilustrações do livro para a turma. Os discentes ficaram atentos e foram participativos.

Apresentamos uma resenha da obra lida aos alunos:

Narra a história de uma bruxa, Samanta, que é comilona e está gorda. Ela deseja ir a um baile, para o qual é convidada, mas antes percebe que não "cabe" em seu vestido. Samanta, então, se submete a um tratamento rigoroso em um SPA: dietas, exercícios são postos em execução; Samanta é acompanhada por seu gato, também obeso. Por fim, ela fica magra e vai ao baile. Neste ponto o livro traz um desenlace surpreendente, ofertando à criança a oportunidade de escolher qual o final que mais lhe agrada. Ou Samanta começa a comer compulsivamente na festa e engorda novamente, ou come de forma comedida e dança elegantemente com o príncipe (KAERCHER; DALLA ZEN, 2010, p. 3).

Concluída a leitura, foi proposto que cada um escolhesse o final preferido e registrasse a argumentação de sua resposta. Das meninas, três escolheram o primeiro final, em que a bruxa dança durante a festa com o galã da história e segue "linda, magra e exuberante". Porém, onze optaram pelo segundo final, em que Samanta prefere a mesa de doces e os come até estourar o vestido. Com relação aos meninos, um optou pelo primeiro desenlace e quatro pelo segundo. O tempo que os educandos levaram para concluir a atividade foi aproximadamente de quarenta minutos. Houve boa aceitação da proposta e, durante a escrita dos textos, os alunos mostraram-se atentos e interessados.

\section{Avaliação dos resultados}

A prática da produção textual é importante para o desenvolvimento e aprimoramento das habilidades na linguagem. Além disso, trazer textos que permitam maior interação do leitor com a obra e a polissemia fomentam a criatividade, já que:

[...] a criatividade instaura o diferente na linguagem na medida em que o uso pode romper com o processo de produção dominante de sentidos e, na tensão da relação com o contexto histórico-social, pode criar novas formas, novos sentidos. Pode realizar uma ruptura, um deslocamento em relação ao dizível (ORLANDI, 2012, p. 26).

Portanto, há a tensão entre o sentido já legitimado, institucionalizado histórica e socialmente, sendo o parafrástico considerado a "matriz do sentido". E a criatividade se produz na busca do rompimento com o que está cristalizado e estabilizado, na busca de efeitos de originalidade. Por conseguinte, nos veículos midiáticos, há muitas construções que investem na construção do sentido parafrástico sobre amizade e aceitação do diferente. E, na amostra da pesquisa, percebemos que a maior parte dos alunos têm acesso a desenhos 
e personagens midiáticos da atualidade que, em geral, manifestam um discurso em que prevaleça a aceitação, o amor-próprio (mais comum nos textos de autoajuda) ou de crítica aos padrões convencionais. Justifica-se assim a escolha dos alunos, em sua grande maioria, pelo final inusitado. Logo, uma das hipóteses que corrobora o resultado é a manifestação desse tipo de discurso nos materiais midiáticos a que os alunos têm acesso.

As sequências discursivas que seguem foram recortadas das produções escritas dos alunos, em que eles deveriam justificar o final escolhido:

SD 1 - O final (em) que Samanta engordou de novo. Por que não importa se você é magra ou gorda - você é do seu jeito não importa como. ( $\mathrm{H}$, menina, 10 anos).

SD2 - O final que eu mais gostei foi o segundo final que ela não se importa com nada e nem com ninguém e come um monte. ( $\mathrm{M}$, menina, 10 anos).

SD3 - Por que eu acho que nós temos que ser felizes naquilo que nós somos. Se você é gorda (o) ou magra (o) não importa. O que importa é ser feliz. (L, menina, 9 anos).

SD4 - O final que eu escolho é o segundo final quando ela come tudo o que tem na mesa porque eu achei engraçado o jeito que ela comeu. ( $\mathrm{H}$, menino, 9 anos).

SD5 - Eu achei o primeiro final melhor porque ela era mais bonita (,) até entrou na fantasia da bruxa. (A, menina, 9 anos).

SD6 - Eu gostei deste final que a Samanta vai a um SPA e perde peso e a mulher faz um vestido. A Samanta coloca o vestido e vai a festa e dança com o príncipe. (M, menina, 9 anos).

Percebemos, por meio das sequências discursivas anteriormente expostas, que a maioria dos alunos optou pelo segundo final e que destes um número maior de meninas produziu um discurso de aceitação e de não interferência da opinião alheia em suas vontades. Foi possível observar a redução da ênfase na valorização da beleza e da conquista do príncipe, embora isso apareça nas SDs 5 e 6. Conforme Foucault $(2008$, p. 126) “[...] em qualquer sociedade, se está preso no interior de poderes muito apertados, que lhe impõem limitações, proibições ou obrigações". Embora a sociedade discorra sobre discursos de autoaceitação, há a formação imaginária alimentada pelo desejo de corresponder ao padrão ideal imposto e sabe-se que, para alcançar tal padrão, é necessário superar limitações, obrigações e proibições (ao estilo contos de fada como Cinderela ou Branca de Neve). O que observamos é que as condições de produção dos sujeitos-alunos, em grande parte, estão levando a um posicionamento diferente dessas limitações e proibições.

E o recorte do menino $\mathrm{H}$, na $\mathrm{SD} 4$, é semelhante ao dos outros três que decidiram pelo segundo desfecho - pelo fato de neste ser produzido o efeito de humor, já que a personagem comeu tanto que o vestido rasgou. É possível também que as crianças queiram brincar com a "leitura em aberto" num "jogo de reversibilidade" (ORLANDI, 2011), característica do discurso lúdico.

Outro fato é que a obra trabalhada permite ao sujeito-aluno lidar com os mecanismos discursivos:

De posse do conhecimento dos mecanismos discursivos, o aluno terá acesso não apenas à possibilidade de ler como o professor lê. Mais do que isso, ele terá acesso ao processo da leitura em aberto. E, ao invés de vítima, ele poderá usufruir a indeterminação, colocando-se como sujeito de sua leitura (ORLANDI, 2011, p. 203). 
Por isso, percebendo a linguagem em seu aspecto discursivo, foi possível que os alunos fizessem parte do mecanismo em funcionamento do discurso, inserindo-se no discurso e, dessa forma, produzindo sentidos, e sendo assim sujeitos de sua leitura. Legitima-se, nesta prática, a ideia de que a escola pode ser produtora de sentidos e não apenas reprodutora.

\section{Considerações finais}

Ao realizar a intervenção pedagógica, imaginava-se que mais alunos teriam escolhido o desfecho clássico e esperado, porque, como a pesquisadora é também professora regente da turma, observa-se cotidianamente uma preocupação com a aparência, sobretudo nas meninas. No entanto, a maioria dos discentes optou pelo final mais improvável, porém engraçado, em que a personagem seguiu as suas próprias vontades, em detrimento ao cuidado com a estética. Logo, percebeu-se que, na prática discursiva em questão, os sujeitos-alunos se filiaram a um discurso de aceitação, amor-próprio, constituindo uma formação discursiva oposta a subjetividades demonstradas por si em suas pequenas ações, ou seja, ao menos no discurso, há a produção do sentido de aceitação.

Com relação à discursividade da língua, vê-se que é importante o trabalho com textos que possibilitam a polissemia, além do debate sobre os efeitos de evidências dos sentidos como ilusão da literalidade. Assim sendo, por meio da escolha dos finais possíveis para a história, vemos que as meninas já não percebem, em seu discurso, que encontrar o príncipe encantado é a sua salvação ou o melhor destino para as personagens femininas. Os discursos sobre o corpo feminino, na grande maioria, levam a uma perspectiva de autoaceitação e autossuficiência, talvez pelos discursos de resistência que pregam o empoderamento feminino, o que é observado em filmes infantis atuais como Valente e Moana. Foi pertinente observar que o corpo gordo da personagem principal não foi questionado nas produções escritas dos alunos. Muitos sujeitos-alunos optaram pela decisão da personagem não se privar do prazer em comer doces, em favor da socialização e da aceitação da sociedade. As formações discursivas em que se inseriram a maioria dos alunos ao enunciarem a justificativa de suas escolhas não reproduziram a ideologia da normalização que impõe regras à manutenção e exposição do corpo.

A partir da análise da atividade realizada, notamos que é pertinente o trabalho pedagógico tendo por ênfase o estudo da linguagem em seu aspecto discursivo, pois com paráfrase e polissemia há o oferecimento da possibilidade de o sujeito-aluno produzir sentidos e texto com criatividade. Assim sendo, a língua não é estável nem evidente, já que, em meio à heterogeneidade discursiva, há contornos de historicidade e subjetividades.

\section{Referências}

CECILIO, Sandra Regina; RITTER, Lílian Cristina Buzato. Leitura e análise linguística: carta do leitor na Revista Ciência Hoje das Crianças. $3^{\circ}$ CELLI - COLÓQUIO DE ESTUDOS LINGUÍSTICOS E LITERÁRIOS, p. 2059-2069, 2007. Disponível em: <http://ple.uem.br/3celli_anais/trabalhos/ estudos_linguisticos/pfd_linguisticos/096.pdf >. Acesso em: 21 abr. 2019.

ERNST, Aracy. Corpo, discurso e subjetividade. In: INDURSKY, Freda; FERREIRA, Maria Cristina Leandro. (orgs.). Análise do discurso no Brasil: mapeando conceitos, confrontando limites. São Carlos: Claraluz, 2007. Disponível em: <http://analisedodiscurso.ufrgs.br/anaisdosead/2SEAD/ SIMPOSIOS/AracyErnst.pdf>. Acesso em: 21 abr. 2019.

FOUCAULT, Michel. Vigiar e Punir: história da violência nas prisões. 35. ed. Petrópolis: Vozes, 2008. 
GREGOLIN, Maria. Análise do discurso e mídia: a (re)produção de identidades. Comunicação mídia e consumo, v. 4, n. 11, p. 11-25, 2008. Disponível em: <http://revistacmc.espm.br/index.php/ revistacmc/article/view/105>. Acesso em: 21 abr. 2019.

INDURSKY, Freda. Da heterogeneidade do discurso à heterogeneidade do texto e suas implicações no processo da leitura. A leitura e a escrita como práticas discursivas. Pelotas: Educat, p. 27-42, 2001. Disponível em: <http://www.leffa.pro.br/tela4/Textos/Textos/Livros/Leitura_e_a_Escrita. pdf\#page=27>. Acesso em: 21 abr. 2019.

INDURSKY, Freda. Discurso, língua e ensino. Especificidades e interfaces. In: TFOUNI, Leda V.; MONTE-SERRAT, Dionéia M.; CHIARETTI, Paula (org.). Análise do discurso e suas interfaces. São Carlos: Pedro \& João Editores, 2011. p. 327-340.

KAERCHER, Gládis Elise Pereira da Silva; DALLA ZEN, Maria Isabel Habckost. Interpretações de crianças sobre as representações de feminilidade e masculinidade na literatura infantil. Seminário Internacional Fazendo Gênero, v. 9, p. 1-8, 2010.

LEMOS, Cláudia T.G. Sobre a aquisição da escrita: algumas questões. In: ROJO, Roxane (org.). Alfabetização e letramento: perspectivas linguísticas. Campinas: Mercado de Letras, 1998.

MEYRICK, Kathryn. Samanta Gorducha vai ao baile das bruxas. São Paulo: Brinque-book, 1995.

ORLANDI, Eni P. Identidade linguística escolar. In: SIGNORINI, Inês (org.). Lingua(gem) e identidade: elementos para uma discussão no campo aplicado. Campinas: Mercado de Letras, 1998.

ORLANDI, Eni P. Discurso e Texto. 2. ed. Campinas: Pontes Editores, 2005.

ORLANDI, Eni P. Análise de discurso: princípios e procedimentos. 9. ed. Campinas: Pontes Editores, 2010.

ORLANDI, Eni P. A linguagem e seu funcionamento: as formas do discurso. 6. ed. Campinas: Pontes Editores, 2011.

ORLANDI, Eni P. Discurso e leitura. 9. ed. São Paulo: Cortez, 2012.

PÊCHEUX, Michel. Semântica e discurso: uma crítica à afirmação do óbvio. 2. ed. Campinas: Editora da UNICAMP, 1995.

PÊCHEUX, Michel. O discurso. Estrutura ou acontecimento. 6. ed. Campinas: Pontes, 2012.

VINHAS, Luciana Iost. Discurso, corpo e linguagem: Processos de subjetivação no cárcere feminino. Tese (Doutorado). Porto Alegre: UFRGS, 2014. Disponível em: <https://www.lume.ufrgs.br/ handle/10183/114410>. Acesso em: 21 abr. 2019. 
